\title{
EESTI JA LÄTI LUULE SÜND SAKSA LAULU VAIMUST II
}

\author{
(Algus Keeles ja Kirjanduses nr 10)
}

LIINA LUKAS

\section{„Ehstländische poetische Blumenlese für das Jahr 1779” ja saksa laul kui rahvavalgustuse vahend Baltimaades}

$\mathrm{N}$ ägime artikli esimeses osas, et Johann Gottfried Herderi ettepanek võtta luule loomisel mõõtu rahvalaulust ei leidnud veel niipea Baltimaade kirjandustes rakendust. Pöörame nüüd tähelepanu teisele 1779 . aasta luulesündmusele, kogumikule „Ehstländische poetische Blumenlese für das Jahr 1779” („Eestimaa poeetiline lillevalik 1779. aastaks”). See sisaldas kolme väljaandja, kirjastaja Johann Friedrich Ernst Albrechti (1752-1814), tema näitlejannast naise Sophie Albrechti (1756-1840) ja Friedrich Gustav Arveliuse (1753-1806) saksakeelsete luuletuste kõrval kolme „maakeelde ümber pandud pala”, mille lähtetekstid olid tuntud saksakeelsed laulud. ${ }^{1}$ Kaks neist („Der Graf bot seine Schätze mir” / „Saks pakkus rikkust minule” ja „Mein! lobt mir doch nur nicht die Nacht!” / „Oh ärge kiitke mulle ööd”) olid Johan Adam Hilleri (1728-1804) koomilisest ooperist „Die Jagd” (esietendus 1770. aastal) pärit aariad. Kolmas almanahhi eestikeelne värsstekst oli anonüümne pastoraal pealkirjaga „Tomas ja Liso”. Võib oletada, et eestikeelseid laule loodi avaldatust rohkem, sest almanahhi eessõnas vihjatakse suurema kogu avaldamise võimalusele (Albrecht [1779]: 5).

Hiller oli oma aja populaarsemaid saksa laulu- ja operetiheliloojaid, kes rajas 1771. aastal Leipzigis laulukooli ja andis välja mitmeid muusikaajakirju. Eriti menukad olid tema koomilised ooperid (nt „Die Liebe auf dem Lande”, „Die Jagd”, „Lisuart und Dariolette”, „Die verwandelten Weiber, oder Der Teufel ist los"), mille libretod kirjutas tuntud luuletaja ja lastekirjanik Christian Felix Weisse. Mitmed neist koomilistest ooperitest ilmusid Riias Hartknochi kirjastuses. Nendesse põimitud aariad olid tuntud ja rahva seas käibel iseseisvate lauludena ning sisaldusid paljudes hilisemates laulukogudes.

Hilleril olid lähedased suhted Kuramaa hertsogi oukonnaga. 1782. aastal juhatas ta Miitavis õuekapelli. Hiller andis välja Baltimaade tuntuima luuletaja Elisa von der Recke (1754-1833) luulekogud ning komponeeris tema luuletustele ka viise. Recke (peamiselt vaimulikku) luulet tõlkis läti keelde terve kogu jagu Gotthard Friedrich Stender (1789). Lätikeelsetes laulukogudes on samuti Hilleri aariate (nt „Ein Mädchen das auf Ehre hielt”) tõlkeid, nii nagu

${ }^{1} \mathrm{Ka}$ saksakeelsed „Blumenlese” luuletused said üsna ruttu pärast ilmumist lauluks. Need viisistas Erfurti muusik Georg Peter Weimar kirjastaja Albrechti palvel, kes andis need koos klaverisaatenootidega välja kohe järgmisel aastal (Weimar 1780). 
ajastu teisegi operetilooja Johann Heinrich Faberi laulude omi (nt operetist „Peter und Hannchen oder die Bezauberten”, 1772). Sel moel on helilooja Hiller aidanud kaasa nii baltisaksa, eesti kui ka läti luule sünnile. Hilleri ja Faberi operetilibretodel oli tihti mõni prantsuse eeskuju, eriti prantsuse näitlejanna ja näitekirjanik Marie Favarti populaarsed näidendid, seega on nendest pärit eesti ja läti tõlked mitmekordsed ülekirjutused.

See kultuurivahetus ei olnud tingimata ühesuunaline, st ei kulgenud vaid Saksamaalt Baltimaadele ja seal saksa keelest kohalikesse keeltesse. Samal aastal, kui ilmusid kaks kõne all olevat laulukogumikku, andis Eestimaal koduõpetajana töötanud muusik Andreas Traugott Grahl Leipzigis välja laulukogu „Oden und Lieder” („Oodid ja laulud”, 1779), mis sisaldanud ka eestikeelseid laule „ühe Eestimaa daami tekstidele” (Recke, Napiersky 1829: 87). Sellest kogust ei ole teadaolevalt säilinud ühtegi eksemplari, kuid tõenäoliselt olid need samad laulud, mille Grahl trükkis hiljem oma noodiraamatus „Lieder und Handsachen für das Klavier und den Gesang” („Laulud ja soolopalad klaverile ja laulmiseks", 1784). Selles leiduvad kaks eestikeelset laulu „Tio tassane ja helde” / „Tiiu, still und gütig” ja „Liesole” / „An Lieschen”, mille teksti autoritena nimetab Grahl Eestimaa daame (Roos 1939: 164-165). Viimast, kevadlaulu, mille originaal on saksakeelne, kuid mis anti välja koos eestikeelse tõlkega, trükiti hiljemgi mitmel pool, näiteks Johann Christoph Petri raamatu „Ehstland und die Esthen” (Eestimaa ja eestlased”) teises köites (Petri 1802: 70-71) ja veel 1840. aastal esindab see laul saksakeelsetes ajakirjandusväljaannetes eesti luulet. ${ }^{2}$

Tiiu-laulu teisend (nn Roosi-laul) trükiti 1787. aastal koos noodiga Põltsamaa koduõpetaja Friedrich Gotthilf Findeiseni (1743-1796) välja antud kuueköitelise lugemiku „Lesebuch für Ehst- und Livland” („Lugemik Eesti- ja Liivimaale") viiendas köites (Findeisen 1787: 472) ning aasta hiljem avaldas sama laulu ka Saksa kirjandusajakiri Der Teutsche Merkur.

Ei ole teada, kas ja kus neid laule esitati. Ilmne on, et Saksamaal üha hoogustuv laulukultuur oli jõudnud ka Baltimaadele. Lihtne rahvalaulu laadis laul (sks Lied im Volkston), mida tuli laulda „pigem rahvalikult kui kunstipäraselt" (Schulz 1785) ja milles oli, nii nagu Herderi sentimentalistlikus rahvalauluesteetikaski, tähtsam tundmus kui poeetiline ilu (Albrecht [1779]: 6), vallutas ka siinsed salongid ja lavad. Kasvupinnas Tartu lauljate liitude (Dorpater Sängerbünden) ja sealt edasi laulupidude tarvis oli loodud.

Millist rolli mängisid selles repertuaaris eesti-ja lätikeelsed laulud? Et eestikeelsel ilmalikul tõlkelaulul oli olemas tarbija, tõendavad nende ja teiste tõlkelaulude mitmed kordustrükid: näiteks esmakordselt 1788. aastal Tallinnas Lindforsi trükist nii põhja- kui ka lõunaeesti keeles ilmunud pingilaulu ${ }^{3}$ „Üks hirmus, ja töest sündinud Luggu, ühest Kornetist, kes oma Frauat ning kaks Last, ühe Moisa-Preili pärast on ärrasurmanud Ning kuida temma sepärrast Mosuhhi-Linnas on sanud ärrahukkatud" trükiti veel aastatel 1816, 1863 ja 1873. Nii mõnigi neist, näiteks mainitud Tiiu-laul või „Saks pakkus rikkust minule” kirjutati hiljem üles rahvalauluna.

${ }^{2}$ Vt Der Ausländer. Eine Unterhaltungsspende für Leser aus allen Ständen worin vorzüglich sehr zuziehende Erzählungen. Wien, 1840; Das Ausland: Wochenschrift für Länder- und Völkerkunde, 1840, kd 13.

${ }^{3}$ Vt Merilai 1991: 14. 
See kõneleb suulise ja kirjaliku kultuuri piiride tinglikkusest: suuline kultuur ammutas ainest kirjalikust ja vastupidi. Baltimaade mitmekeelses kultuuriruumis oli keeltevaheline kultuuriülekanne igapäevane nähtus.

Kui esimesed eestikeelsed ilmalikud luuletused sündisid rokokoo operetlikus laulukultuuris, siis lätikeelse ilmaliku luule algus on sügaval valgustusajastu vaimuliku luule traditsioonis, mida kehastab kõige silmapaistavamalt Stender. Ta andis 1754. aastal välja lätikeelse vaimulike laulude kogu. Läti keele grammatika (Stender 1761) lisa jaoks tõlkis ta läti keelde saksa tuntuima valgustusluuletaja Christian Fürchtegott Gellerti valme ning kimbu saksa valgustuskirjaniku Barthold Heinrich Brockese õpetlasluulet. Ta pidas küll rahvalaulu läti luule alguseks, ent mitte selle võimalikuks eeskujuks, soovitades arendada läti luulet küpse tõlkeluule abil. See arusaam oli kooskõlas rahvavalgustusliku haridusprogrammiga, mis nägi ette „meie rahvuse kultiveerimise" (Kultivierung unserer Nation) arenenud rahvaste kultuuriliste mustrite ülevõtmise abil. Nii nagu Stender nägi ette läti luule edendamise Brockese tõlgete kaudu, visandas Peter Heinrich von Frey eesti luule arendamise programmi järgmiselt:

Et valmistada meie rahvust [unsere Nation] ette talle kohaseks kultuuriks, tunduvad eeskujulikud luuletused kasuliku vahendina. Ainult vähemalt esialgu ei ole algupärandid soovitatavad [---]. Heade tõlgete või ilusate, juba olemasolevate luuletuste eesmärgipäraste jäljenduste abil saaks meie rahvus samasugused oppetlikud eeskujud, nagu iga praegu haritud [rahvus] kunagi kreeklaste, roomlaste ja heebrealaste poeetiliste meistriteoste üha truumate koopiate abil. (Frey 1813: 24-25)

Tegelikult rahvavalgustuslik haridusprogramm - maakeelse luule harimine tõlkeluule abil - siiski ei töötanud ei Brockese ega kreeklaste meistriteoste tõlgetes. Küllap osutusid need liiga keeruliseks nii tõlkijaile endile kui ka maarahvast adressaadile. Peagi leiti tõhusam vahend - tõlkeline saksa laul. See sobis paremini rahvavalgustuse sihtrühmale, kes lugemise asemel oli harjunud värsstekste laulma: tööd tehes või puhkehetkedel rahvalaulu, kirikus ja palvemajades vaimulikku laulu. Luule polnud isiklik, vaid kollektiivne elamus. Vaimuliku laulu ja rahvalaulu kõrvale tekkiv (kirjalik) ilmalik luule oli seetõttu samuti laul. XVIII sajandi viimase veerandi ja XIX sajandi esimeste kümnendite eesti- ja lätikeelsete värsistuste lähtetekstid olid pärit saksakeelsetest populaarsetest laulukogudest ja laulumängudest, mitte luulekogudest. Need avaldati saksakeelsetes laulukogudes koos nootidega ja veidi hiljem eesti- ja lätikeelsetes laulukogudes.

Esimese maakeelse autorilaulu kogu pani kokku Johann Jakob Harder 1766. aastal ja see sisaldas Gellerti tekstide tõlkeid läti keelde. Gellerti 1757. aastal ilmunud vaimulike oodide ja laulude kogu „Geistliche Oden und Lieder” oli väga menukas, tema laulud levisid viisistatult, leides koha nii kiriku lauluraamatutes kui ka ilmalikes laulukogudes. Paraku jäi Harderi kogu ilmumata ja selle käsikiri leiti alles hiljuti Läti riigiarhiivist. Nii ei saanud see mõjutada tõlkelaulu arengut, kuid osutab ajastu maitsele.

Stenderi järgmine lätikeelne laulukogu „Jaunas singeses pehz jaukahm meldeijam par gudru islusteschanu” („Uued rahvalikud laulud kenade viisi- 
dega ajaviiteks", 1774) annab tunnistust Stenderi teisenenud luulemaitsest. Brockese valgustuslik-didaktilise ja Gellerti vaimuliku luule asemel pakub Stender nüüd just nimelt laule, oode ja eleegiaid, mis olid Göttingeni hiieliiduga (Göttinger Hainbund) saksa luulesse tulnud uues, lüürilises ja rahvalikus laadis ja milles käsitleti isamaa-armastust, sõprust, armastust, perekondlikkust jt kodanlikke väärtusi (vt Daija 2017: 42-43), sekka veel rokokoolikku anakreontilist luulet (kogumikus on esindatud autorid Ludwig Christoph Hölty, Johann Martin Miller, Johann Heinrich Voß, Matthias Claudius, Johann Wilhelm Ludwig Gleim, Christian Adolph Overbeck). Lätikeelsete tõlgete juures on ära toodud eeskujuks olnud saksakeelsete laulude algusread, mille puhul on pigem siduv nende laulude viis kui sõnad. Stenderi laulukogu oli väga menukas, aastatel 1783 ja 1785 ilmusid selle kordustrükid ja 1789 . aastal teine osa. Stenderi teeneks oli läti keeles saksa klassikalise meetrika ja riimitehnika juurutamine ja võib arvata, et see õnnestus tal, vahest juba keelte sarnase struktuuri tõttu, paremini kui tema kolleegide võrreldav tegevus Eestimaal.

Stenderi eeskuju nakkas ja 1780. aastal andis Pinki pastor Johann Adolf Stein välja laulukogu „Jaunas swehtas dseesmas, stahstischanas un zittas singes” („Uued vaimulikud laulud, ballaadid ja teised rahvalikud laulud”), mis sisaldas nii Miitavi lauluraamatust („Mitauisches Gesangbuch”) pärit kirikulaulude kui ka valmide ja rahvalike laulude, eriti Gellerti populaarsete laulude tõlkeid.

Stenderi poeg ja mantlipärija Alexander Johann Stender (1744-1819) viis isa letofiilset tegevust edasi ka luule alal. Ta avaldas lätikeelse juhuluule kogumiku „Jaunagada vēlēšanas” („Uusaastasoovid”, 1793), jätkates nii eelmise sajandi juhuluuletraditsiooni, ning 1805. aastal ilmus ka tema koostatud laulude, valmide ja muinasjuttude kogumik „Dziesmas, stāstu-dziesmas, pasakas” („Laulud, lugulaulud, muinasjutud”), mis lisaks isa lätindusest tuttavatele autoritele, nagu Gleim, Claudius, Overbeck, Christian Friedrich Daniel Schubart ja August E. F. Langbein, pakkus August Bürgeri ballaadi „Die Entführung, oder Ritter Karl von Eichendorff und Fräulein Gertrude von Hochburg” ja Friedrich Schilleri „An die Freude” lätikeelse tõlke. See laulurepertuaar on tervenisti pärit Mildheimi lauluraamatust, millel on allpool põhjust pikemalt peatuda.

Noorema Stenderi kogud, nii nagu mitmed hilisemad samalaadsed (nt K. R. Girgensohni „Stāsti, pasakas, dziesmas un mīklas” („Jutud, muinasjutud, laulud ja mõistatused"), 1823), olid populaarses taskuraamatu või almanahhi formaadis väljaanded, mis sisaldasid eri žanrides ilukirjanduslikke palu, kujunedes sellisena rahvavalgustuse tähtsaks meediumiks (Böning 1998). Neist almanahhidest eristub oma eesmärkidelt 1804. aastal ilmunud „Līksmības grāmata” („Rõõmu raamat”), mille autor oli Apriḳi pastor Karl Gotthard Elverfeld (1756-1819). See oli kindla kavatsusega komponeeritud tekstikogu, mis ei järginud enam rahvavalgustuslikke eesmärke ega olnud mõeldud meeldivaks ajaviiteks, vaid taotles inimese esteetilist kasvatust saksa klassikalise idealismi vaimus (Taterka 2011). Kesksel kohal on raamatus Schilleri ood „An die Freude", millest oli saanud ajastu tähtsaim luuletus. Selle avaldas kohe järgmisel, 1805. aastal ka noorem Stender oma laulukogus ning oma tõlked sellele pakkusid ka Jakob Florentin Lundberg ja Karl Friedrich Hugenberg. Võrdlu- 
seks: eesti keeles avaldati Schilleri ood alles 1813. aastal, kuid siis kogunisti kahes tõlkes: Otto Reinhold von Holtzi (1757-1828) „Römu kitus” Eesti-Ma Rahwa Kalendris ja Jakob Wilhelm Reinhold Ewerthi „Laul römo ülle” ajakirjas Beiträge.

Uusi esteetilisi sihte pidas silmas ka aastatel 1826-1827 ilmunud Hugenbergeri kaheosaline kogumik „Derīgs laika kavēklis” (Kasulikku meelelahutust”), mis sisaldas ainult luulet, kuid Goethe, Schilleri, Bürgeri ja Johann Peter Hebeli tõlgete kõrval juba ka algupärandeid.

Eesti tõlkeluule lugu on tunduvalt hilisem ja hajusam. Esimene eestikeelne laulukogu pealkirjaga „Monned Laulud” ilmus alles 1806. aastal, lätikeelsest 30 aastat hiljem. Enne seda oli eestikeelsete laulude avaldamiskohaks eestikeelne kalender - väljaanne, millel oli suur lugejaskond. Tallinnas Lindforsi trükikoja väljaandel ilmunud Eesti Ma-Rahwa Kalendris trükiti aastail 17961798 kolm Johann Gottlieb Schwabe (1754-1800) laulu („Lapse uinutamise laul”, „Kewade laulda” ja „Laul”).

Kogumik „Monned Laulud” sisaldab üheksat lauluteksti peamiselt Reinhold Johann Winkleri (1767-1815) ja von Holtzi muganduses. Nagu Stenderi kogus, pole siingi märgitud lähtetekstide autoreid, kuid väljakujunenud tava järgi on antud lähtetekstide algusread, mis osutavad populaarsele saksa lauluvarale. Nende seas on Hölty pea igas saksa laulukogus trükitud „Lebenspflichten” („Rosen auf den Weg gestreut” / „Kurwa meelt jahhutada”) ja „Elegie bei dem Grabe meines Vaters” („Nutto laul ühhe issa haua jures"), aga ka vähem tuntud poeetide levilaule, näiteks austria luuletaja Franz von Spauni „Ich habe viel gelitten auf dieser schönen Welt” („Ma ollen monda näinud"), mille ta kirjutas kümne aasta pikkuses vangistuses Prantsuse revolutsiooni meelsuse eest 1790. aastail, või rahvalauluna käibel olevad „Der blinde Harfenspieler” („Ich spielt als knabe ungefangen” / „Ühhel pimmedal laulda, kelle silmad rouged on ärra rikkunud”) ja „Arm und klein ist meine Hütte” (Weike on kül minno maia”) ning juba „Blumenleses” 1779. aastal trükitud Hilleri aaria „Der Graf bot seine Schätze mir” (,Saks pakkus rikkust minule").

Kohe järgmisel, 1807. aastal ilmus esimene ühe tõlkija laulukogu: Winkleri „Eesti-ma Ma-wäe söa-laulud”, mis oli mõeldud Napoleonile vastupanuks loodud maamiilitsa võitlusvaimu tugevdamiseks. Valimik sisaldab viit saksa eeskujudest (Overbeck, Claudius, Schubart) lähtuvat laulu, millest nii mõnigi sai eesti varase luuleklassika osaks, nagu nt „Nüüd, mehhed, olge tuggewad” (Schubarti „Auf! Auf! Ihr Brüder, und seid stark”), mille võib leida ka veel XIX sajandi lõpu lugemikest (nt C. R. Jakobsoni omast). Baltimaise tekstiversiooni Schubarti laulule lõi saksa keeles Christian Wilhelm Brockhusen (1768-1842) (Brockhusen 1807) ja selle mugandas omakorda kohe samal aastal eesti keelde Tartu ülikooli toonane eesti keele lektor Friedrich David Lenz (1745-1809) (Lenz 1807).

Winkler pani kokku veel teisegi laulukogu, mis selle lüroeepilise iseloomu tõttu avaldati postuumselt hoopis pealkirja all „Juttud” (1816). See sisaldab kahtteist luuletust: enamasti valmid, kuid leidus ka ballaade, paar eleegilist luuletust ja filosoofilist oodi. Selleski kogus on Winkler lähtunud saksa valgustusliku luule eeskujudest (Gellert, Gleim, M. G. Lichtwer, Bürger, A. Blumauer). 
Lõunaeestikeelse lauluvara eest hoolitses eelkõige Gustav Adolph Oldekop (1755-1838). Tema esimesed, anonüümselt trükis avaldatud luuletused „Talwe laul” ja „Römo laul” ilmusid 1811. aasta Grenziuse Eesti-Ma-Rahwa Kalendris, „Haina laul” 1822. aasta Tarto ma-rahwa Kalendris. Neli laulu ilmusid 1823. aastal ajakirjas Beiträge, kus antakse ühtlasi teada, et huvi korral võiks autor selliseid luuletusi välja anda terve kogu (Oldekop 1823: 150), mis siiski ei ilmunud. Oldekopi laulud levisid ja läksid käibele rahvalauludena ning säilinud on mitu käsikirjalist lauluvihikut tema lauludega (nt Eesti Kirjandusmuuseumis asuv „Römu laulu raamat”, mis sisaldab 14 Oldekopi loodud lauluteksti, vt ka Vinkel 1985: 12-13). Siingi kohtame juba tuttavat laulurepertuaari. „Römo laul” (käsikirjades ka pealkirja all „Päsokenne”) on tõlge tuntud saksa laulust „Nur keck herein”, „Ello rõõm” Johann Martin Usteri sõnadele „Freut euch des Lebens” (1793) loodud laulust. „Pimmeda innimisse kaibdus” on lõunaeestikeelne variant populaarsest laulust „Der blinde Harfenspieler”, mis esines ka kogumikus „Monned Laulud” jne. Nii mõnigi Oldekopi lauludest võib olla algupärand, autori enda sõnul näiteks laul pealkirjaga „Päiwlik”.

Oldekopi ajendas eesti keeles luuletama otsene vajadus eestikeelse laulurepertuaari järele. Naaberkihelkonna Kanepi pastor Johann Philipp von Roth (1754-1818) asutas 1804. aastal esimese kihelkonnakooli Eestis ja selle õppeainete hulka kuulus ka koorilaul. Puudus oli sobivatest lauludest ja nii sündis koostöös Oldekopiga eestikeelne koorilaul. Ka Oldekopi repertuaari aluseks on populaarsed saksa laulud. Eriti palju on nende seas helilooja Johann Abraham Peter Schulzi viise tuntud luuletajate (Claudius, Schubart, Christian Segelbach, Langbein) sõnadele. Schulz oli rahvuslikus laadis laulu propageerija ja edendaja, kelle mitmeosaline kogu „Lieder im Volkston” (1782) osutus väga menukaks, ilmudes mitmes kordustrükis (vt allpool). Samuti on Oldekopi repertuaaris Hilleri laule ning „Noriko Jummalaga jätmise” laulu tuli laulda Max von Knebeli populaarse laulu „Vergiss mein nicht, wenn dir die Freude winket" viisil, kuigi nende laulude sisud ei kattu.

XIX sajandi esimestel kümnenditel olid eesti ja läti laulude (nii tõlkelise kui ka rahvaluule) peamiseks avaldamiskohaks ajakirjad, vastavalt Beiträge zur genauern Kenntnis der ehstnischen Sprache ja Magazin der LettischLiterärischen Gesellschaft. Magazin avaldas lisaks juba läti keeles tuntud autoritele (Claudius, Voß, Gellert, Gottlieb Konrad Pfeffel) ka märksa nõudlikumat luulet, näiteks katkendeid Friedrich Gottlieb Klopstocki „Messiasest” ning Goethe ja Schilleri ballaade (nt viimase „Bürgschaft” („Käendus”) ilmus 1829. aastal koguni kolmes erinevas tõlkes). Märgiline on Magazini 1830. aasta teise köite kolmas number, mis sisaldab sada lehekülge lätikeelset lugemisvara. Lätikeelse luule adressaadi osas ei ole siin veel täit kindlust. Kuigi nimetatud ajakirjanumber on varasematest erinevalt läbivalt lätikeelne ja mõeldud ,jagamiseks ka „meie rahvusele [unsere Nationalen]"” (Magazin 1830: III), on näiteks Voßi heksameetrites idülli tõlke juures siiski veel saksakeelne märge, et see „pole mõeldud lõbustama meie rahvust, vaid kurioosumina läti keele tundjatele ja sõpradele" (Magazin 1830: 69).

Beiträges ilmus nii vaimulikku, rahva- kui ka kaasaegset tõlkeluulet, nii et see oli foorum, kus suuline ja kirjalik laulu- ja luuletraditsioon kohtusid. Tõlkeluulest ilmus esimestes numbrites Gellerti („Der Blinde und der Lahme” / „Jalloto ja Pimme”), Bürgeri („Das Lied vom braven Mann” / „Laul 
ausast mehest") ja J. L. Ewaldi valme Winkleri või Frey tõlkes, kuid tõlkeluule osakaal kahanes ajakirjas edaspidi rahvalaulu kasuks. 1823. aastal (XVI vihikus) ilmusid juba nimetatud Oldekopi neli laulu ning 1832. aastal (XX vihikus) Schwabe „kolm laulukest” (Drei Liederchen) saksakeelsete pealkirjade all „Der Sommer”, „Der zufriedene Bauer” ja „Freundschaft”. Schwabe tekstidele komponeeris viisi Riia linnateatri muusikadirektor Anton Ludwig Ohmann (1775-1833), kes oli mõnda aega varem töötanud kontsertmeistrina Tallinnas.

1814. aastal andis Johann Heinrich Rosenplänter välja eesti luule antoloogia „Lillikessed”, mis sisaldas kuut luuletust. Need olid Frey tõlgitud Gellerti valmid „Waene ning rikkas” („Der Arme und der Reiche”), „Lonkjad” („Das Land der Hinkenden”) ja näivsurma eest hoiatav „Panne surno tähele” („Lied wider die Verwahrlosung der Scheintodten”), Winkleri tõlgitud „Nekrutide laul” (Schubarti „Auf! Auf! Ihr Brüder, und seid stark”), varem Eesti Ma-rahva Kalendris ilmunud „Römo Kitus” (von Holtzi tõlge Schilleri oodist „An die Freude”) ning „Talupoja laul”.

Siiski leidub Rosenplänteri pärandis rohkem eestikeelset luulet, kui seda avaldada jõuti. Nii näiteks ei jõudnud trükki paljud Oldekopi laulud ja kahetsusväärse kaotusena eesti luule jaoks Kristian Jaak Petersoni luule tervikuna.

Nägime, et eesti- ja lätikeelne tõlkeluule sünnib laulust. Laulutekstid algselt küll luuletustena loodud - olid hakanud elama oma anonüümset, rahvalaululikku elu, saanud menukate laululoojate abil lauldavateks lauludeks ja rändasid sellisena ühest populaarsest laulukogust teise, mõnikord koos nootide ja helilooja nimega, kuid enamasti ilma algse teksti autorit mainimata.

Millistest neist laulukogudest lähtusid meie maakeelsete laulude tekstid? Seda ei ole lihtne välja selgitada, kuna laulukogusid, mis neid laule sisaldasid, ilmus väga palju. Näiteks võib mitmeid Stenderi ja hilisemate autorite tõlkelaule leida Berni kirjastaja ja kompilaatori Johann Georg Heinzmanni 1782. aastal ilmunud laulukogust „Die Feyerstunden der Grazien” („Graatsiate jõudetunnid”). Menukad olid Schulzi laulukogud (nt „Gesänge im Volkston”, 1779; „Lieder im Volkston” („Laulud rahvalikus laadis”), 1782, 1785, 1790), samuti Johann Heinrich Egli 1790. aastal viisistatud laulukogu „Lieder der Weisheit und Tugend zur Bildung des Gesangs und des Herzens” („Tarkuse ja vooruse laulud laulu ja südame harimiseks”). 1798. aastal ilmus neljaosaline „Allgemeines Liederbuch des deutschen Nationalgesanges” („Saksa rahvuslaulu üldine lauluraamat”) jpt. Samasse moodi kuuluvad ka juba nimetatud Grahli laulukogud.

Neist menukaim, sobivaim ja mõjukaim kohalikele tõlkijatele ainet pakkunud laulukogu oli Rudolf Zacharias Beckeri (1752-1822) välja antud „Das Mildheimische Liederbuch” („Mildheimi lauluraamat”, 1799), mis koondas varem ilmunud laulukogude paremiku ja kujunes läbi aegade populaarseimaks. 1837. aastaks oli sellest ilmunud kümme uustrükki ja laulude arv neis üha suurenes (esmatrükis oli 518 laulu, hiljem 800). Kui umbes samal ajal ilmunud rahvalaulukogusid (Johann Gottfried Herderi „Stimmen der Völker in Liedern” või Clemens Brentano ja Joachim von Arnimi koostatud „Des Knaben Wundernhorn") luges ja laulis vaimustunult vaid väikesearvuline haritud eliit, kujunes Mildheimi lauluraamatust tõeline rahvaraamat, mille laulud kui nad ei olnud seda juba varem - said rahvalauluks just selle kogumiku 
kaudu. Siitkaudu läks käibele lauluvara, mida võis hiljem leida saksakeelsetest kooli-, tudengi- ja Liedertafel'i laulikutest.

Lauluraamat oli üks meede Beckeri rahvavalgustuslikus kasvatusprogrammis, mille ta sõnastas 1785. aastal kirjutises „Versuch über die Aufklärung des Landmannes” („Plaan talupoegade valgustamiseks”). Seda plaani rakendati edukalt ka Baltimaade talupoegade seas. Beckeri 1788. aastal ilmunud „Noth- und Hülfsbüchlein für Bauersleute, oder lehrreiche Freuden- und Trauergeschichte des Dorfes Mildheim” (Häda- ja abiraamatuke talupoegadele ehk õpetlik lugu Mildheimi küla rõõmudest ja muredest”, 1788), mis oli koostatud plaanile vastavalt, oli omal ajal Saksamaa populaarseim ilmalik raamat, levides aastakümneid üha uutes kordustrükkides ja üha suuremates tiraažides - see käib ka raamatu eesti- ja lätikeelsete tõlgete kohta. ${ }^{4}$

Mildheimi lauluraamat sisaldas erineval kunstilisel tasemel ja erinevas stiilis (valgustusliku ratsionalismi, sentimentalismi, tormi ja tungi rahvaliku luule vaimus) laule. Ühtlasest kunstilisest kontseptsioonist olulisem oli väljaandja Beckeri rahvavalgustuslik idee, mis nägi laulus talupoegade moraalse kasvatuse tõhusat vahendit. Seades eesmärgiks katta lauludega kogu inimlik tegevusväli, kutsus ta üles kaasaegseid luuletajaid looma „moraalseid tundmusi äratavaid laule" igaks elujuhtumiks. Beckeri koondatud laulud olid mõeldud ühiskonna madalamatele rahvakihtidele, mistõttu pidid nad olema võimalikult „selged ja arusaadavad, ei tohtinud sisaldada vihjeid asjadele ja mõistetele, mis asuvad väljaspool rahva vaatevälja", ei tohtinud sisaldada mütoloogiat, abstraktseid mõisteid, kuid pidid olema nii oma väljenduses kui ka ideedes kujundirikkad ja ülevad. Laulud pidid äratama ja edendama häid kõlbelisi tundmusi, mis juhiksid kestva ja tõelise inimliku õndsuseni, kuid seda oma seisuse piires ja sellele vastavalt. (Weissert 1966: 23)

Beckeri programm vastandus Herderi arusaamale rahvast ja rahvalaulust. Herder ei näinud viimases ülalt alla suunatud rahva kõlbelise kasvatuse vahendit, vaid alt ülespoole suunatud rahva tundmuse väljendust, millest peaks mõõtu võtma kõrgkultuur. Beckeri uus lauluvara pidi asendama rahvalaulu, mis tundus rahvavalgustajatele kõlvatu, mõttetu ja õilsa tundmuseta, ja nii oli Mildheimi laulukogu pigem romantilise paradigma rahvalauluidee vastand, olles samal ajal rahvalaulust mõjutatud. Uus lauluvara kasutas mitmes mõttes ära talurahvale tuttavlikke jooni, ühendades rahvalaulu laadi ja kirikulaulu religioossuse. Kogumiku šrift, kahes veerus tekst ja temaatiline liigendus meenutas pigem kiriku lauluraamatut kui luulekogu ja küllap tegi see kogumiku lähedasemaks neile, kes polnud seni ühtki luuleraamatut käes hoidnud.

Rahvavalgustuslik esteetilise kasvatuse programm sobis ka Baltimaade lauluvara jaoks, mille loojateks olid XIX sajandi algul eranditult pastorid, mitte enam eelnenud sajandi lõpul laulumänguaariaid tõlkinud mõisnikud või mõisaprouad. Kõige autoriteetsemalt esindasid seda programmi Kuramaal pastor Gotthard Friedrich Stender, tema jälgedes läti keele alal ja Liivimaal Piṇki pastor Johann Adolph Stein, põhjaeesti keele alal Kadrina pastor Joachim Gottlieb Schwabe, Jüri pastor Reinhold Johann Winkler, Keila pastor

${ }^{4}$ Arveliuse eestikeelne tõlge ilmus aastal 1790, Liborius Bergmanni lätikeelne tõlge aastal 1791, mõlemad kärbitud kujul (vt selle kohta Daija 2011, 2017). 
Otto Reinhold von Holtz, lõunaeesti keele alal Põlva pastor Gustav Adolph Oldekop. Viimase tuginemise Mildheimi lauluraamatule on tuvastanud Aarne Vinkel (2002: 518).

Mildheimi lauluraamatust pärit laulud leidsid tõepoolest tee ka eesti ja läti lugejate südameisse, seega võime väita: tänu baltisaksa rahvavalgustuslikule eestkostele muutus eesti ja läti luule eeskujuks rahvalaulu asemel saksa laul, mis - saksa kultuurikolonialismi võsuna - kujundas veel kaua eesti ja läti (kirjalikku) luule- ja laulukultuuri.

Rahvalaul kehtestas end esteetilise nähtusena Baltimaade filoloogilises diskursuses mõnikümmend aastat hiljem, 1840. aastatel Läti Kirjanduse Seltsi, Õpetatud Eesti Seltsi ja Eestimaa Kirjanduse Ühingu tegevuse kaudu, kuid rahvalaulu kirjalik ,järellaul” teostus alles eesti rahvuseeposes „Kalevipoeg”, mille koostaja Friedrich Reinhold Kreutzwald tugines rahvalaulu eeskujule. Seal täitis rahvalaul kõiki Herderi ette antud funktsioone: ajaloolist, esteetilist, pedagoogilist ja poliitilist. Ent see järellaul ei teostunud enam lüürilise, vaid hoopis eepilise huvides, ja see on juba omaette teema.

Artikli valmimist on toetanud Euroopa Liidu Regionaalarengu Fond (Eestiuuringute Tippkeskus) ning see on seotud Eesti Haridus- ja Teadusministeeriumi uurimisprojektiga IUT20-1 „Eesti kirjandus võrdleva kirjandusuurimise paradigmas”.

\section{Kirjandus}

Albrecht, Johann Friedrich Ernst [1779]. Vorbericht. - Ehstländische poetische Blumenlese für das Jahr 1779. Wesenberg: Albrecht, lk 1-8.

Br ockhus en, Christian Wilhelm 1807. Zuruf an die Landmiliz Livlands; im Fall sie gegen den Feind zöge. Ein Versuch von C. W. Brockhusen. Riga: Häcker.

Bön ing, Holger 1998. Almanache, Taschenbücher und Kalender im literarischen Leben Norddeutschlands und ihre Bedeutung für die Volksaufklärung. - Literarische Leitmedien. Almanach und Taschenbuch im kulturwissenschaftlichen Kontext. (Mainzer Studien zur Buchwissenschaft 4.) Toim Paul G. Klussmann, York G. Mix. Wiesbaden: Harrassowitz, lk 31-46.

Daij a, Pauls 2011. „Häda- ja abiraamatuke” rahvavalgustusliku ettevõtmisena Läti alal XVIII sajandil. - Keel ja Kirjandus, nr 8-9, lk 628-642.

D a ij a, Pauls 2017. Literary History and Popular Enlightenment in Latvian Culture. Cambridge: Cambridge Scholars Publishing.

Findeisen, Friedrich Gotthilf (koost) 1787. Lesebuch für Ehst- und Livland. Fünftes Stück. Schloß Oberpahlen: Grenzius.

Frey, Peter Heinrich 1813. Über die Ehstnische Poesie. - Beiträge zur genauern Kenntniss der ehstnischen Sprache, II. Pernau, lk 15-43.

Len z, Friedrich David 1807. Liwlandi maa-Soldatile kui nemmad peaksid waenlaste wasto söddima minnema. Tartu: Grenzius.

Merilai, Arne 1991. Eesti ballaad 1900-1940. Tartu: Tartu Ülikool.

Magazin, herausgegeben von der Lettisch-Literärischen Gesellschaft 1830. Zweiten Bandes drittes Stück. 
Old e k o p, Gustav Adolph 1823. Vier Lieder von Herrn Pastor Oldekop. - Beiträge zur genauern Kenntniss der ehstnischen Sprache, nr 16, lk 150-158.

Petri, Johann Christoph 1802. Ehstland und die Ehsten, oder historisch-geographisch-statistisches Gemälde von Ehstland. Ein Seitenstück zu Merkel über die Letten, Bd 2. Gotha: K. W. Ettinger, lk 70-71.

Recke, Johann Friedrich, Napier sky, Carl Eduard 1829. Allgemeines Schriftsteller- und Gelehrten-Lexikon der Provinzen Livland, Ehstland und Kurland, Bd 2. Mitau: Steffenhagen.

R o os, Jaan 1939. Ühest vanast noodiraamatust. - Eesti Kirjandus, nr 4, lk 161166.

Schulz, Johann Abraham Peter 1785. Vorbericht. - Lieder im Volkston. 1. Theil, 2. Aufl. Berlin: Decker.

Stender, Gotthard Friedrich 1761. Neue vollständigere Lettische Grammatik, Nebst einem hinlänglichen Lexico, wie auch einigen Gedichten. Braunschweig: im Fürstl. grossen Waisenhause. (2. trükk Mitau: Steffenhagen, 1783.)

Stender, Gotthard Friedrich 1789. Elīzes divpadsmit svētas dziesmas, latviešu valodā pārtulkotas no tā vecā mācītāja Stendera. Mitau: Steffenhagen.

Taterka, Thomas 2011. Läti talupoeg astub kirjandusväljale. Läti rahvusliku kirjanduse sünd kunstiajastu vaimust. - Keel ja Kirjandus, nr 8-9, lk 660-674.

Vinkel, Aarne 1985. [Eessõna.] - Gustav Adolph Oldekop, Suve õdang. Tallinn: Eesti Raamat, lk 7-23.

Vinkel, Aarne 2002. Uusi andmeid G. A. Oldekopi luule allikate kohta. - Keel ja Kirjandus, nr 7, lk 518.

W ei mar, Georg Peter 1780. Lieder mit Clavierbegleitung, für Liebhaber eines leichten und fliessenden Gesanges. Reval-Leipzig: Albrecht und Compagnie.

Weissert, Gottfried 1966. Das Mildheimische Liederbuch. Studien zur volkspädagogischen Literatur der Aufklärung. Tübingen: Vereinigung für Volkskunde.

Liina Lukas (snd 1970), PhD, Tartu Ülikooli kultuuriteaduste instituudi maailmakirjanduse dotsent, (Ülikooli 16, 51003 Tartu), liina.lukas@ut.ee

\section{The birth of Estonian and Latvian poetry from the spirit of the German lied. Part 2}

Keywords: folk song, Estonian poetry, German lied, theory of poetry, J. G. Herder, lyrical poetry

In the same year with the second volume of J. G. Herder's folklore collection addressed in Part 1 of the present article, the poetry almanac "Ehstländische poetische Blumenlese für das Jahr 1779" was published. Besides the German-language poetry of its three publishers - publisher Johann Friedrich Ernst Albrecht (1752-1814), his actress wife Sophie Albrecht (1756-1840) and Friedrich Gustav Arvelius (1753-1806) - the almanac presented three Estonian translations of popular German songs. In addition, musician Andreas Traugott Grahl, who had been tutoring in Estonia, published a collection called "Oden und Lieder" (1779) in Leipzig, which is reported to have also contained some Estonian-language songs 
with the lyrics coming from "an Estonian lady". So the singing culture booming in Germany had made its way to the Baltics. The simple song in folk style (Lied im Volkston) conquered the local parlours and stages and soon also farmhouses. The source texts of the Estonian and Latvian versifications representing the last quarter of the $18^{\text {th }}$ and first few decades of the $19^{\text {th }}$ century came from popular German songbooks and song games, not from poetry collections. So the lyrics, despite their origin as poems, started living their own anonymous life as folk songs: having aquired (owing to some popular song composers) the status of singing songs, they travelled from one collection to another, sometimes with tunes and the composer's name, yet mostly without mentioning the author of the lyrics.

It is hard to pinpoint the songbooks which happened to provide the source texts for our Estonian lyrics, as the variety of such songbooks was enormous. The most popular, suitable and influential songbook of those available for the local translators was "Das Mildheimische Liederbuch" (1799) published by Rudolf Zacharias Becker (1752-1822), which brought together the best songs previously published and became the most popular songbook of all time in the German language space. While Herder's folklore collections were read and sung enthusiastically only by a small number of educated elites, Mildheim's songbook became a real people's book, whose songs became, if they were not already, folk songs through this very collection. This was the source of numerous songs to be found later in the songbooks of schools, students and Liedertafel. Songs from Mildheim's songbook also found their way into the hearts of Estonian and Latvian readers, and many of them were later written down as folk songs. Thus we can argue that due to the Baltic German intellectual guardianship Estonian as well as Latvian poetry took example not from their own folk song but from the German lied, which - as an offspring of German cultural colonialism - was to mould the Estonian (written) poetic and singing culture for long to come.

Liina Lukas (b. 1970), PhD, University of Tartu, Institute of Cultural Research (Ülikooli 16, 51003 Tartu), Associate Professor of World Literature, liina.lukas@ut.ee 